\section{CUT DOWN ON PAPER FORM FILLING}

With more and more patients having access to smart phones and emails, it makes sense to extend your paperless system directly to your patient's mobile device. Patient Portal by iSmile allows your patients to fill out medical history forms and patient questionnaires on their mobile phones, tablets or desktop computers.

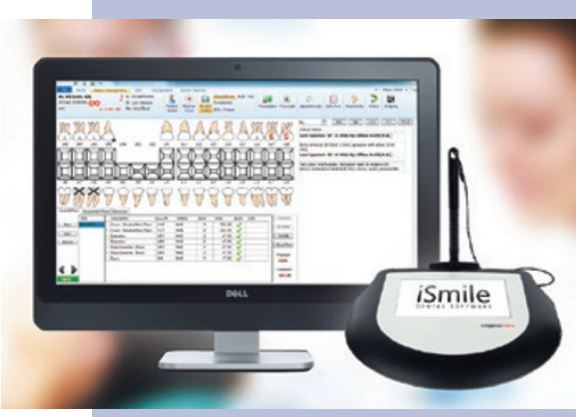

Forms are automatically emailed to patients, allowing them to securely fill them out online prior or post appointment. Not only does this give your patients a more connected experience, it also means less hassle filling out forms at reception.

Once the online forms are back in your practice management system they can be verified and signed by the patient using a digital signature pad. Patient Portal further allows you to use your own choice of tablet (iOS or Android) for form filling at the practice, in case there are patients that don't have access to a mobile device.

iSmile's powerful reporting system allows you to display data from patient feedback forms in a range of formats so you can analyse trends across different time periods to see how your business's customer service is improving.

Give iSmile a call today on 08454681287 for more information or visit www.ismiledental.co.uk.

\section{ALL-NEW INTUITIVE ACCESS AND SPECIAL OFFERS}

Leading dental supplier The Dental Directory has relaunched its website. www.dental-directory.co.uk has been in development for more than 12 months and has been created in response to the changing needs of The Dental Directory's 10,000 customers.

In addition to providing more intuitive access to The Dental Directory's over 20,000 strong product range, including its recently acquired facial aesthetic and skin rejuvenation brand, Med-fx, the website also introduces a host of new business management and training features designed to offer a unique resource to the sector, including:

- Online account management designed with the needs of multiple practices in mind

- Sub-user purchasing functionality and budgeting

- Budget controls to help you manage your monthly spending

- An intuitive search function which recommends product offers and promotions based on buying history

- Order tracking

- Access to invoices to help manage your account

- Mobile functionality - you can access your account from your mobile or tablet, which means you can order whenever and wherever you are

- Quick shopping

- Order history.

The Dental Directory has also used the improved functionality to offer exclusive online campaigns and provide customers with even greater value such as its 5 Golden Deals, which had a different offer on Dentsply products each day during a week in December, and Pink Friday in November, which offered an additional discount for online orders.

The Dental Directory is also now the only dental supplies provider in delivery on orders placed up to six o'clock on the previous day. www.dental-directory.co.uk the UK that can offer free next day

\section{SWIFT, EFFECTIVE WHITENING AT HOME}

The Philips Zoom! QuickPro 6\% is the latest addition to the Philips Zoom! EU portfolio of whitening products and addresses the concerns voiced by many dental professionals as it offers convenience to the patient, without taking up valuable practice chair time or requiring custom made trays. It also fills the void left by the removal of over-thecounter tooth whitening products from the market. Philips Zoom! QuickPro 6\% is clinically proven to whiten up to four shades in as little as four days (average shade reduction; actual results may vary).

No trays are needed and, provided the patient is judged suitable for treatment by a dentist, a dental professional simply walks through the first application with the patient and dispenses the product, saving valuable chair time.

Philips Zoom! QuickPro can be used as a stand-alone procedure; following a chairside treatment; or to 'top up' previous whitening. A general appointment can become a whitening appointment, thanks to the convenience of the five-minute application, making it easy and cost effective to add whitening to any appointment, especially routine hygiene sessions.

Many patients who used to buy OTC whitening products still want to whiten with the convenience of a home-use kit. Philips Zoom! QuickPro provides an affordable but professional whitening solution with that convenience.

More information is available from www. philips-tsp.co.uk/bdia.

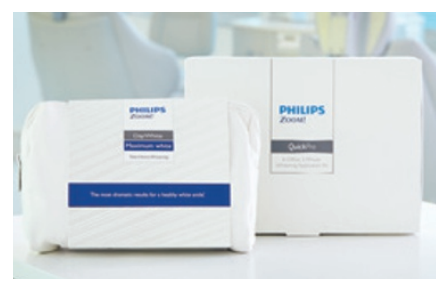

\section{DENTAL DISINFECTION PRODUCTS BACK BY} POPULAR DEMAND

Safe4 is delighted to have returned to the dental sector, once again offering its highly effective range of disinfection products to dental practices across the UK.

From the Disinfectant Cleaner to Instrument Cleaner and Safe4 Nitrile Gloves, all solutions have been designed with the dental professional in mind.

In addition, with extensive experience in the dental market and a clear passion for keeping your staff and patients safe, the team behind Safe 4 are on hand to offer any advice or support you may need.

Safe 4 has one of the most ethical ranges of products available in the UK and has always maintained its primary principle of delivering safe products that protect both the end user and the environment.

By offering its products directly to you, Safe4 strives to deliver a more personalised service tailored to the type of business you run and the demands you face.

To discover more about the exciting products now available from Safe4, contact the team today on 01606 591900, email info@safe4disinfectant.com or visit www.safe4disinfectant.com. 